\title{
Mapping health care innovation : tracing walls \& ceilings
}

Citation for published version (APA):

den Hertog, J. F., Groen, M., \& Weehuizen, R. M. (2005). Mapping health care innovation : tracing walls \& ceilings. MERIT, Maastricht Economic Research Institute on Innovation and Technology. MERITInfonomics Research Memorandum Series No. 007 https://doi.org/10.26481/umamer.2005007

Document status and date:

Published: 01/01/2005

DOI:

10.26481/umamer.2005007

Document Version:

Publisher's PDF, also known as Version of record

\section{Please check the document version of this publication:}

- A submitted manuscript is the version of the article upon submission and before peer-review. There can be important differences between the submitted version and the official published version of record.

People interested in the research are advised to contact the author for the final version of the publication, or visit the DOI to the publisher's website.

- The final author version and the galley proof are versions of the publication after peer review.

- The final published version features the final layout of the paper including the volume, issue and page numbers.

Link to publication

\footnotetext{
General rights rights.

- You may freely distribute the URL identifying the publication in the public portal. please follow below link for the End User Agreement:

www.umlib.nl/taverne-license

Take down policy

If you believe that this document breaches copyright please contact us at:

repository@maastrichtuniversity.nl

providing details and we will investigate your claim.
}

Copyright and moral rights for the publications made accessible in the public portal are retained by the authors and/or other copyright owners and it is a condition of accessing publications that users recognise and abide by the legal requirements associated with these

- Users may download and print one copy of any publication from the public portal for the purpose of private study or research.

- You may not further distribute the material or use it for any profit-making activity or commercial gain

If the publication is distributed under the terms of Article $25 \mathrm{fa}$ of the Dutch Copyright Act, indicated by the "Taverne" license above, 


\section{MERIT-Infonomics Research Memorandum series}

Mapping Health Care Innovation: tracing walls and ceilings

Friso den Hertog, Marjan Groen \& Rifka Weehuizen

2005-007

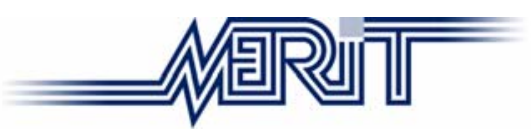

MERIT - Maastricht Economic Research Institute on Innovation and Technology

PO Box 616

6200 MD Maastricht

The Netherlands

T: +31433883875

F: +31433884905

http://www.merit.unimaas.nl

e-mail:secr-merit@merit.unimaas.nl

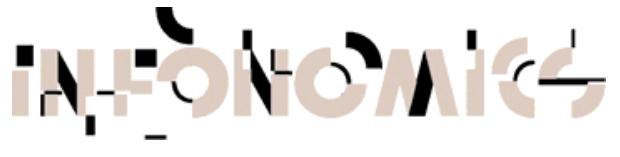

International Institute of Infonomics

c/o Maastricht University

PO Box 616

6200 MD Maastricht

The Netherlands

T: +31433883875

F: +31453884905

http://www.infonomics.nl e-mail: secr@infonomics.nl 
MERIT Research Memorandum series

Mapping Health Care Innovation: tracing walls and ceilings

Friso den Hertog, Marjan Groen \& Rifka Weehuizen

2005-007

f.denhertog@merit.unimaas.nl

r.weehuizen@merit.unimaas.nl

marjan.groen@merit.unimaas.nl 


\title{
Mapping Health Care Innovation: \\ Tracing Walls \& Ceilings
}

by

Friso den Hertog, Marjan Groen and Rifka Weehuizen

April 1, 2005

MERIT/University Maastricht

\begin{abstract}
Health care is in need of innovation on many strands. Patient-centered care appears to be the key to the realization of the main objectives: service quality, cost reduction, access, patient satisfaction and the quality of working life. Innovation, and more precisely, the diffusion and implementation of new methods, new techniques and new processes and systems appears to be a difficult task. Consequently, there is a strong need for knowledge about innovation processes in health care and the drivers and barriers affecting these efforts. This paper presents a framework for mapping innovation processes in health care services. The framework consists of two axes: (1) the horizontal axis of the health care process and the inter-functional walls which can complicate innovation efforts, and (2) the vertical axis of the echelons of power, which often create ceilings too impermeable to permit effective learning and decision making. The study is based on the experiences gathered in Publin, a running research network supported by the Fifth Framework Program and Innoflex, which ended in 2003.
\end{abstract}

JEL codes: I11, O31 (Analysis of Health Care Markets, Innovation and Invention: Processes and Incentives) 


\section{Introduction}

There is an urgent need for innovation in health care. That call is heard in almost any developed and less developed country. A recent OECD study (Docteur and Oxley 2003) indicates that costs have reached an all times high. Cost control measures in the 1980s and 1990s appear not to have addressed the root causes of the growth of health care spending. It is remarkable in this respect that the rising costs of modern technology and new drugs are regarded (Docteur and Oxley 2003) as cost drivers rather than cost reducers. At the same time a number of OECD countries are concerned that care spending restrictions have gone too far and hurt health care performance. The quality of health care is the second strand where reforms appear to be needed. Waiting lists are a well-known phenomenon in many countries. Safety is an issue that cannot be regarded as self-evident. Studies (Kohn et al. 2000) based on information derived from root-cause analysis of specific incidents suggest that poor design of health care delivery systems, rather than technical incompetence among individual professionals underlies the majority of the problems. Surveys within five OECD-countries (Blendon et al. 2002, p. 189) show that many health care consumers are dissatisfied with their health care system and a vast majority of these consumers indicates that "fundamental changes” are needed, or that the system has to be rebuilt completely. Dissatisfaction is also widespread under the care providing professionals themselves. Job dissatisfaction is a major reason for physicians to withdraw from practice (Burke 2003), and restructuring of care services, mostly resulting in the increase of the patient-to-nurse ratio has a strong negative impact on the satisfaction among nursing staff (Williams et al. 2001). Finally, even in countries, where universal insurance coverage is regarded as a political norm barriers for access to health services appear to rise, both with regard to specific under-privileged groups and in terms of restrictions of specific risks in the healthcare policies (Docteur and Oxley 2003).

Debates about innovation are taking place at almost any level of the health system: from the hospital floor, to the management- ranks and the level of the policy-makers. In these discussions, there is one basic hope. That hope is, that the problem areas mentioned above are not fundamentally a set of contradictory demands. That means that improvements in the efficiency of the system are not by definition an infringement on quality of care, and that quality improvements are imaginable without spending extra money. The hope is that the improvement of the quality of care is the key to controlling the cost of the care. In this way 
effective treatment results in higher satisfaction of patients, nurses and doctors, faster recovery and better final outcomes, and as a result: in lower costs. Most advocates of this logic take a patient-centered view on the changes needed in the health service, meaning that patient care should be redesigned so that health care resources are organized around patients rather than around various specialized departments or functions of care providing systems (Sherer 1993, p.14). This perspective has inspired health professionals, managers and politicians in many countries. There is a wide variety of developmental, or experimental projects throughout the OECD-countries, both on the higher system level, as on the management and operational level of health care. Especially the many experiments at the service level of health care show that health care can be made more effective, safe, patientfriendly, faster and more efficient (Schrijvers et al. 2002). However, studies like these also show, that innovation in health care is a difficult process.

The implementation and diffusion of new solutions, rather than their invention, seems to be the vulnerable phase of the innovation (Adler et al. 2003, Denis et al. 2002, Schrijvers et al. 2002). Sackett et al.(1997, p.7) point out that present medical practice has a firm base in scientific evidence and stress that the real issue today is how much of that evidence is actually applied in the front lines of patient care. This might be regarded as the big paradox in health care innovation: while the technological and professional competencies have been progressing at a fast pace, the functioning of the health care system as a whole appears not to have profited from this progress. Research from the last decade indicates that a complex of factors is responsible for the malfunctioning of the innovation funnel in health care. Qualitative research (Adler et al. 2003) into the implementation of clinical pathways shows the importance of the organizational learning capacity in determining the success of change efforts in hospitals. Other authors (Striem et al. 2003) point to the impact of the professional autonomy on management induced change programs. Medical professionals, for example, appear to regard Total Quality Management (TQM), as a break with the firmly entrenched tradition of professional self-control of quality, and as a result do not commit themselves to the change efforts (Adolfini 2003).

All these observations underline the importance of knowledge about the process and context of health care innovation. Research in this area is still in its infancy (Tabak and Jain 2000). This applies to the service sector as a whole (Miles, 2004). Service organizations have been neglected by innovation researchers because they were assumed to be "innovative 
laggards” (Miles 2004, p.63). However, the undeniable growth of the service sector as a part of our economy, has led an increasing number of researchers to turn their attention to service innovation. The pioneering work of Coombs (2004), Miles (2004), Tether and Metcalfe (2003) indicates that the relevance of models, typologies and concepts from the manufacturing industry for the study of service innovation is rather limited. Service innovation takes a wide variety of forms, but shows to have a number of characteristics, which need to be analyzed. The crucial role of the customer in the innovation process is one of these characteristics. It is recognized now that innovations take place within the context of intensive interactions between the service provider and the service user, as well between the service provider and equipment suppliers (Tether and Metcalfe 2003). These complex interactions constitute multiple “systems of innovation”. Tether and Metcalfe (2003, p.2) argue that these systems often develop around identifiable sequences of problems, which are themselves framed by a number of contingencies (including the regulatory, cultural and technological). That means that the "problem" or the "opportunity" can be considered as the heart of the system of innovation. Both writers point out that as the problem (or opportunity) changes, or is redefined, the system can change and for the same reason the agents and the relationships between these agents can change too. The implication is that there is not a "single system" of innovation in services, but instead innovation takes place in a multitude of different systems or patterns, which involve agents from different sectors.

This characterization seems applicable to health care as it points up the complex nature of the innovation process. At the same time, there is an urgent need for knowledge about the context and process of innovation in health care that can help to make innovation programs more effective and less time consuming. To date one can see the emergence of a new line of research dedicated to innovation, its diffusion and implementation in health care. The number of studies remains rather limited (for example: Denis et al. 2002, LemieuxCharles et al. 2002, Metcalfe and James 2001, Robinson et al. 2003) and the field is still fragmented. It is suggested in this paper that a framework for understanding the innovation within the health care context might help to accumulate knowledge in this domain.

The present paper aims to contribute to the development of such a framework. The paper is meant to map the routes innovations have to travel through the health care system before they finally become implemented. The emphasis is on managerial, organizational and institutional barriers for diffusion and implementation. The paper follows a systems 
perspective (Carlsson et al. 2002). A map of the health care systems is used to allocate patterns of innovations. Two basic system dimensions are distinguished. The primary process of health care is referred to as the horizontal dimension. The cooperation between functions and disciplines that contribute to the primary process is regarded as a crucial factor for innovation. The second, and vertical dimension concerns the different system levels at which policy-makers, managers and professionals are working. The paper tries to identify the walls in the primary process that have to be leveled, and the ceilings between different system levels that have to be broken through in order to free the way for effective innovation.

The description of the innovations patterns is done from a patient-centered perspective. The focus is on the downstream part of the innovation trajectory, the diffusion and implementation of innovations in the primary process ("front-end") of health care. It is the area, where the final impacts on patients and care providers become visible. The paper first describes the patient-centered perspective and the three basic forms of health care innovation., and then elaborates on the two basic dimensions of the innovation system. The implications for further research, and innovation management conclude this paper.

\section{Methods}

This paper was born out of the participation in two EU-funded research projects: INNOFLEX (www.innoflex.org.uk) and Publin (www.step.no/publin). The projects developed a research line concerning innovations in health care services and were, and are carried out by networks of more than eight European research centers. The primary aim of the INNOFLEX project was the exchange of knowledge and experience among the participating hospitals, and the transfer of that learning to a wider audience. This project showed how difficult it is to compare and integrate case material from the participating research groups. Site visits and workshops in which researchers and hospital representatives made it possible to share each-others experiences and to make interpretations of the observations. In this sense, the project might be regarded (Engelstad and Gustavsen 1993) as a "network project". The second project is carried out in a similar setting, which might be characteristic for many EUsponsored projects. The experiences that were gathered in the first project, were used by the researchers as input for the second project. Publin was more explicitly aimed at theory development. At the start of the project it had been recognized, that the researchers needed more common ground to exchange their findings and to embed the theory development 
process. On the one hand this setting is far more complex than in multiple case studies where theory building is carried out by one researcher or one team of researchers (see: Eisenhardt 1989). However, the advantages have also become evident in the course of this project. The setting offers the possibility to build theory in an iterative way: going forth and back between the observations, the interpretations by the network members, and the framework in progress. In this respect the effort might be regarded (Strauss and Corbin 1990) as the theory building, grounded in observations made in the course of the project. In this paper we make use of the explorative efforts in the Publin project. Discussions took place during 4 workshops, and in depth interviews involving 34 health care managers, clinicians and policy makers. The authors gratefully made use of the project's progress documents, and many inspiring discussions in the Publin network. The feed back of the framework in progress might be regarded as the most valuable input for this paper.

\section{Patient-centered care}

"Patient-centered care" is more than a socially desirable concept. The concept represents a fundamentally different perspective on the operations of health care services. A perspective which runs parallel to the commercial equivalent of customer-centered (rather than provider-centered) service. Patient-centered care means that (Sherer 1993, p. 14)

(1) as many services as possible are put as close as possible to patients,

(2) work is redefined by desegregating job tasks and providing staff with the necessary support, skills, education, and training,

(3) meeting the needs of patients, not of departments and disciplines.

This perspective implies the integration and decentralization of functions close to the patient, interdisciplinary teamwork and shared decision-making. This approach is also referred to as care for the whole patient, because it does not restrict the care to one or a few aspects of the patient, but deals with the whole person (for example: www.dukehealth.org ). In the concrete language of the practice of health care this means that a team of professionals pays attention to the whole situation of the patient, not only in terms of his or her medical condition, but also with regard to his or her functioning in wider systems: the family, work and school. Integrated (to avoid using the word "holistic") care starts with prevention and extramural care and runs across the walls of the intramural care, back to the living and working environment of the patient and his or her family. Many health care institutions, all over the world have 
adopted this perspective to communicate their intentions. See for example: $\underline{w w w . g o o i-}$ noord.nl, www.buffalohospital.org and www.planetree.org (see box 1)

\section{Patient centered care}

At Buffalo Hospital, every employee knows that you are our first priority. Our services are designed to meet all of your needs in an atmosphere that promotes healing and comfort. We want to make what can be a stressful situation as comfortable as possible for you and your family. We believe it is important to involve and educate you and your family about your medical condition and treatment options.

\section{Nursing care second to none}

Our nursing staff's responsiveness and level of personalized, skilled care is second to none. Survey results show that the strong, personal connection our nurses make with their patients stands out as one of the most satisfying parts of their hospital experience.

By making your health care experience more positive, we believe we can help you heal better.

\section{Box 1: Patient-centered care (www.buffalohospital.org)}

The perspective of patient-centered care provides inspiration for the design and development of health care services. This view implies the shift of focus from the development of individual crafts towards process development and organizational learning (McLaughlin and Kaluzny 2000). Clinical pathways are regarded as instruments for this learning process. Clinical pathways can be regarded as interdisciplinary road maps or guides for action given a particular diagnosis, based on consensus among care providers and are in line with the state-of-art (Adler et al. 2003, p.33). They address all care providers. Clinical pathways are meant to promote clinical and organizational practices grounded in scientific evidence (Denis et al. 2002). "Evidence-based decision making” aims to close the gap between what is known and what is used in practice (Denis et al. 2002, p.60, cf. Sackett 1997). Essential in these approaches is the reference to medical practices and medical knowledge. The patient-centered perspective is also used in innovations with labels from managerial language: total quality management (Adinolfi 2003), re-engineering (Ho and Kidwell 1999), continuous improvement (Adler et al. 2003). One might hypothesize that these differences in wording reflect the "ownership" of the various approaches rather than the basic principles. 
Modern information and communication technology (ICT) is often seen as a key to the improvement of the health care delivery system in general (Wholey et al. 2000). ICT can both be regarded as a driver of re-engineering and as a support, a tool, of the clinical primary process. It is argued (Simpson 2003) that ICT can be a powerful tool for realizing the development of patient centered care. The use of hand held technology, for example, can be used to bringing nurses back to the bedside (Simpson 2003). The cost cutting strategies of the 1980s and 1990s, invariably targeted nurse staffing levels and put the bedside care process under increased pressure. A new generation of clinical information systems (CIS) can reduce the time spent on non-care tasks and give "nurses the one thing they really need more oftime” (Simpson 2003, p. 14). In the same vein the internet is opening new ways to bridge geographical distances and to bring care closer to the patient (Robinson and Savage 2003).

\section{The map as a representation of the system}

The maps to be drawn in this paper can be regarded as spatial representations of the innovation system and are meant to gain insight in the emergence of these patterns. The focus of this study is on the diffusion and implementation phase of health care innovation. The observations above imply that the maps should be drawn from the perspective of the patient. Or in systems language: the build up of the picture of the system is bottom up rather than top down. The primary process of health care is the starting point for the exploration of the innovation system. Secondly, the maps should offer the possibility to visualize the multiple levels of decision-making and organizational learning (cf. Tucker and Edmondson 2003). Observations like the ones above indicate that interactions between different levels are frequently problematic in health care innovation. Finally, the maps should show the feed back mechanisms within the health care innovation system, the basic question being: how is the impact of innovation monitored at different system levels?

In line with sociotechnical systems theory (De Sitter et al. 1997) the map of the health care innovation system is built up along two basic dimensions: (1) the structure of the primary process (or: production structure), in which inputs are transformed in systems outputs, and (2) the structure of the planning and control functions (or: the control structure). The primary process is represented in the mapping as the horizontal axis. The horizontal axis serves to identify the needs for integration of and cooperation between the different connections of the health value chain. The vertical axis represents the control structure and positions the key 
echelons of management and policy-making: from the operational, or peer level, management level to the systems (or policy) level.

The systems approach is broadly accepted as a tool for the analysis of economic and technological change (Carlsson et al. 2002). This paper focuses on the analysis of the innovation system in health care. The function of the innovation system is according to Carlsson et al. (2002, p.235): “... to generate, diffuse, and utilize technologies (physical as well as technical know-how) that have economic value”. A system consists of components, relationships and attributes.

We start our mapping exercise with a tour of the constituting elements of the system. First of all there are the components. Carlsson et al. (2002) describe components as the operating parts of a system (p.234). These can be actors (e.g. patients, health care professionals, managers, politicians), organisations (e.g. hospitals, nursing homes, community care centres, insurance companies, professional bodies, patient organisations, manufacturers, universities), institutions (e.g. regulatory laws, inspection, watchdogs) or artifacts (e.g. drugs, diagnostics, equipment, implants). We will not try to make a complete list of possible components. As Carlsson et al. (2002) point out, the system boundaries, the actors involved, the networks and institutions may vary depending on how we choose the level of analysis. Tether and Metcalfe (2001) make a similar point when they say that the problem or opportunity at the heart of the 'system of innovation' becomes the focusing device around which the system is developed. Thus, as the problem or opportunity changes, or is redefined, so the system can change, changing the agents involved and the relations between these agents. In the present paper we are not concerned with one particular innovation or set of innovations, but rather with the performance of the health care system as a whole and the main features of that system.

The second element of a system consists of the relationships between the components. Again, much will depend on the specific innovation under study. Tether and Metcalfe (2001) describe how systems that generate innovation can be regarded as sets of micro systemic elements that are created around sequences of problems or opportunities and involve shifting patterns of interaction as new problems or opportunities emerge and draw upon different kinds of specialised knowledge.

Finally, the third element of a system consists of the attributes; the properties of the components and the relationships between them Carlsson et al. (2002). These attributes characterise the system, they are the features which are crucial for understanding the system 
and are related to the function or purpose served by the system. The main features of an innovation system are the capabilities of the actors to generate, diffuse, and utilize technologies that have economic value. Our mapping exercise will result in the description of a number of attributes of the healthcare innovation system.

In the course of this paper we will draw on studies that provide in depth analysis of innovation at the micro level, so that we can see the components and relationships in action. This allows us a peek into the system and gives the necessary empirical grounding for our analysis. We will however concentrate on the issues addressing the effectiveness of the system as a whole to perform its function: innovation of healthcare delivery.

\section{The horizontal axis: health care as a process}

Health care is often portrayed (Minzberg 1979) as a professional bureaucracy. This means that the functions (disciplines) are the basic building blocks of the system. A formal system of rules and regulations serves to integrate these specialized units. Within this context the professionals have a high degree of autonomy. Traditionally the professional autonomy of doctors has been regarded as a cornerstone of health care. The functional organization can be regarded as a fruitful environment for the development and implementation of new methods and health technologies that have their roots in the medical specialisms. These innovations often have a scientific or technological origin, for example use of lithotripters, laser-guns and psycho-pharmaceuticals. We propose to call them functional or clinical innovations, because they have their roots and main impacts in the disciplines, or professions of health care. Research and training centers, equipment and drugs suppliers, and the communities of practice of the professionals form the system of innovation in which new treatments can be developed. Modern cataract surgery, by which the natural nontransparent lens is removed and replaced by a plastic lens, which is placed inside the eye, is an example of a complex functional innovation. This innovation (box 2) is based on decades of technical and clinical development and has become an icon of modern medicine. 
"You have a cataract in your right eye" says the ophthalmologist. "A small, hardly burdening operation will solve the problem. In this hospital we do more than 5000 of these operations a year. The surgery itself takes less than half an hour. You can go home an hour later". The patient, coming back from the surgery, can hardly imagine what development work had to be carried out, in order to design this seemingly routine operation, which today can be performed in most local medical centers. It took more than three decades to perfect the original idea of the British eye doctor Harold Bingham. Until the eighties the technique was viewed with considerable hostility by the ophthalmic profession. Today it the most frequent outpatient surgery among people above the age of 65. The development of this functional innovation has been a long path of trial and error. That path has been the search for new operating techniques, new materials, and new equipment. Crucial in this development has been the technique, developed by Charles Kelman in the United States, used to fragment the cataract by ultrasound and remove the debris by a pump mechanism. The foldable lens, surgical microscopes and new anaesthetic methods have been other complementary innovations required to reach the present level of ophthalmic treatment. Metcalfe and James (2000), made an excellent case study into the development of the IOL-surgery, and their report has been used in writing this box. The case study shows that during these three decades of ophthalmic research and development, a very complex system of innovation co-evolved with the innovation itself. The ophthalmic community of practice, leading medical centers, material and equipment manufacturers formed a system of distributed capabilities and complementary assets.

The innovation process does not stop there. The availability of crucial new knowledge, new evidencebased medicine does not in itself (Van de Ven and Schoemaker 2002) change the practices and processes in the health care service. That requires complex changes in the health care delivery system. The final social impact of the IOL-innovation is in fact only realized on the moment the delivery system is ready to perform the treatment as a routine and the health insurance companies pay for the treatment. One might speak in this respect of the "diffusion phase" of innovation. However, from the perspective of the health care services it might still be better to talk about "real innovation". The eye clinic in Rotterdam is a good example. The clinic was almost closed, more than ten years ago. The management and clinical staff made the decision for a radical streamlining of the treatment process in order to turn away from the closure. The clinic is now regarded as a highly successful example of health care innovation. In order to reach that level of performance a coalition of management and professionals had to rebuild the whole organization and all of its care processes. That means the introduction of innovations in almost every part of the service process, including new clinical pathways, new technologies, parallel production lines for the main types of treatment, logistics, surgery and care teams, training programs, patient education and reconstruction of the building.

Box 2: Functional innovations and process innovations: the intra-ocular lens (IOL) 
Our first explorations in the literature showed a wide variety of actors involved in health care innovation, and of drivers and barriers of change. Health care appeared to be the stage where many professionals, managers and policy-makers (and patient-organizations) are involved in numerous efforts to develop and implement new service patterns and systems. Schrijvers et al. (2002) show that care can be made more effective, safer, faster, patientfriendly, efficient and professionally satisfying. The researchers describe 21 innovation projects in the Netherlands that make everybody a winner: the patient, the doctor, nurse and tax-payer. However, the diffusion and implementation of these good and often proven ideas in health care as a whole appears to be a serious problem. Many writers have pointed to the gap between what is known and what is used in practice (Denis et al. 2002, Lemieux et al. 2002, Sackett et al. 1997, Schrijvers et al. 2002).

Research into the diffusion process of functional ("technological” or "medical”) innovations is still in its infancy. We still lack the knowledge to understand (Denis et al. 2002, p.61) why some less solidly supported health care innovations are widely adopted, while others with apparently stronger scientific support remain underused. The recent study of Denis et al. (2002), comparing diffusion of four innovations (low molecular weight heparin for deep vein thrombosis, laparoscopic cholecystectomy, multiple use of dialysis filters and assertive community treatment) indicates that the adoption is more likely to take place in contexts where the benefits and risks connected with the new practice fit with the maps of the interests, values, and power distribution of the actors and their organizations. Overadoption of laparoscopic cholecystectomy, can according to the authors, be explained by the presence of a strong pro-adoption coalition, consisting of patients, hospitals and insurance companies. Research into the management of technological innovation in health care appears to be of increasing importance because of its role as major driver of health cost (Docteur and Oxley 2003, Fuchs and Garber 2003). Too much money is invested in the development of high-end, complex technologies, and too little is invested in (“disruptive”) technologies that simplify complex problems (Christensen 2000, Fuchs and Garber 2003). Driving forces of the decision-making process remain unclear in this context.

Process innovations are of a different nature. They concern the innovations that are implemented in the whole sequence of treatments and care activities patients undergo. In 
economic terms one might speak of the "health care value chain". In this view health care is regarded as a system of interconnected subsystems for prevention, intake, treatment, care and aftercare. These subsystems (see figure 1) are mostly part of institutions of organizations (like hospitals, nursing homes, rehabilitation centers and home care) or are operated by individual medical professionals (family doctors, physiotherapists and visiting nurses), and not to forget: by the family and volunteer aid. The thick arrow in figure 1 represents the broad pathway for patients with a certain type of disorder, and the thin arrow the pathway traveled by an individual patient.

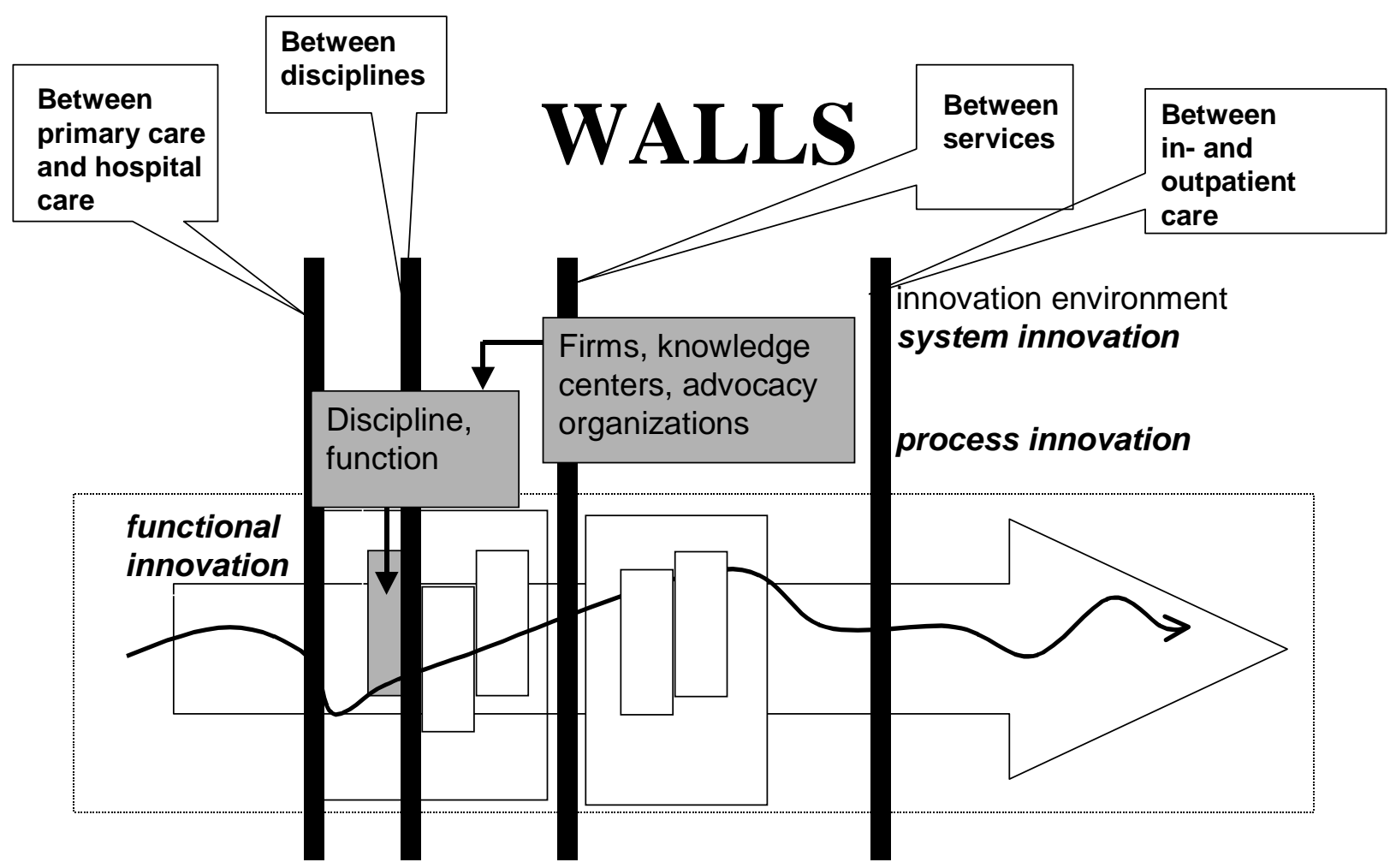

primary care $\rightarrow$ hospital $\rightarrow$ revalidation $\rightarrow$ homecare

Figure 1: Health care as a process.

Functional innovation in health care can be compared to the design of production tools in industry. Innovation in the health care process is similar to the design of a production process as a whole. A fundamental characteristic of process innovation is that most of the 
improvements of productivity and quality are realized by integration, cooperation and adjustments between the subsequent subsystems. Process innovation is by definition crossfunctional. To date, the development of clinical pathways can be considered as the most predominant process innovation in health care. One might regard clinical pathways not only as a formal system that safeguards the use of state-of-art medical practice, but also (cf. Adler et al. 2003) as a means to organize care process. This implies that professionals have to become aware, that evidence-based medicine requires more than formal protocols: it requires new organizational forms in which new ways of treatment can be embedded. As medical knowledge and know how advances, the pathways have to be maintained continuously. The aim of clinical pathways is in the first place the improvement of the quality of the care process as a whole (Field and Lohr 1992). This aim is close to process innovations and not far away from change programs with more “business-like” labels, like Total Quality Management (TQM), Re-engineering, and Continuous (Clinical) Improvement. The basic idea is that the quality of the actions is to be monitored at each step of the process in order to safeguard the final quality the “customer” may expect. In this view, quality pays out, because effective treatment is the best way to control costs.

McLaughlin and Kaluzy (2000) argue that process innovation in health care can be considered as part of a more fundamental development: the unfolding industrialization of health care. Industrialization represents a move away from the craft model where health care is “... being delivered by professionals who practiced an individual craft or art, learned by apprenticeships, work independently in a decentralized system, tailored to each individual situation using processes that were not recorded nor explicitly engineered, and were held personally accountable for performance and financial outcomes” (McLaughlin and Kaluzy 2000, p. 74). The writers forecast a development in which health care will move through process improvement and enhancement toward mass customization. The "focused factories" or "specialty hospitals" might be considered (Casalino et al. 2003) as the icon of this industrialization and rationalization process (see: box 2 and 3). In analogy with the modern production lines of car producer Toyota, health care entrepreneurs try to outcompete and outperform traditional facilities by dedicating staff, equipment, and management attention to one specific types of disease.

These developments are not only a source of revenue, but also of controversy (Voelker 2003). Part of the professionals fears that the standardization of medical processes, as advocated in the development of clinical pathways infringe upon their professional autonomy and flexibility (Timmermans and Berg 2003). The focus of health care services on "standard 
cases” is criticized because it could lead to unfair cost advantages by "cherry-picking” (Casolina et al. 2003).

The Deacon hospital in Voorburg (The Netherlands) is on its way to become a focused factory. The concept originated in the manufacturing industry, and is increasingly used for hospitals and wards that are focused on and equipped for the delivery of one type of care for a clearly defined category of patients. Well-known examples are the Shouldice clinic for groin hernia in Toronto and the cataract production line of the eye hospital in Rotterdam. However, nowhere in the world are the principles of focused factory are being used at the scale of a complete hospital. "Here in Voorburg, we want to be a center of excellence for varicose veins, gallbladders and groin hernia," says surgeon Koning. "To be effective you have to build a large body of experience and preferably work in steady teams. That's the way to become better and faster. By using the same operating room for the same type of surgery, no special arrangements are needed. When you do ten of the same operations at the same day, with the same team, you are improving all the time. Crucial is the selection of patients. Patients with complications are not fit for treatment in a focused factory. They will be treated in our sister hospital in Delft" (After: De Volkskrant, February 7th, 2004)

Box 3: The focused hospital

Modern information and communication technology (ICT) is supposed to play a key role in this rationalization process (Wholey et al. 2003). ICT is expected to free health care providers from the tyranny of paperwork. Given this promise (and the high price that has to be paid for that promise), it is remarkable that little is known about the progress that health care services have made in fulfilling that promise (Wholey et al. 2003). The available data show that most health care services have developed considerable administrative system capacity, and that relatively little work has been completed developing clinical systems and integrating clinical with administrative systems. Today, the basic discussion is about the big step health care institutions have to make: from island automation and systems integration towards the implementation of a basic information infrastructure. Such an infrastructure is a basic requirement for the cross-functional collaboration. It does not require much fantasy to see that ICT is crucial for the implementation of almost every type of process innovation. At the same 
time one has to conclude that the same divide between management-driven and clinicaldriven change is evident here.

Cross-functional cooperation is the most important prerequisite for process innovation. In recent literature the lack of that cooperation is mentioned as one of the most serious barriers against process innovation. Adler et al. (2003, p.22) followed the introduction of clinical pathways in seven pediatric hospitals for a year and speak about the striking lack of horizontal communication systems. The earlier comparative case comparison of Savitz et al. (2000) in four American integrated delivery systems pointed in the same direction. Adinolfi (2003) studied the implementation of Total Quality Management in seven Irish and seven Italian hospitals and made a similar observation in both countries. She saw little evidence of team-working across entire specialties or groups of specialties in TQM projects. Illustrative in this respect is the finding in a study on work attitudes of nursing department employees, that job tension and job withdrawal attitudes are negatively associated with inter-department cooperation rather than with intra team cooperation (Carson et al. 2001).

Professional autonomy is regarded by most writers as the underlying source of resistance. It appears that walls and barriers between functions and disciplines have to be pulled down. This applies both to the functions within the walls of a health care institution (intramural cooperation) and across the walls of intra and extra-mural services. This does not exclusively concern the interaction between professionals. Process innovation also requires a basic change in managerial perspective. Management is challenged to change its focus from optimizing the performance of separate functional units toward optimizing the final outcomes of the health care process as a whole. Box 4 gives a good and a bad example.

A lady in her mid 80s is admitted to a general hospital. She has a problem with her esophageal (or: gullet). The treatment she has to undergo, the stretching of the esophageal opening, is no pleasure. After the treatment she has to learn to eat again, or better, swallow solid food. That can be a rather painful experience. Nurses used to sit at the bedside of such patients to "talk the food inside". The risk is, that when they do not try, patients will keep eating soft food like yoghurt and custard. That will substantially increase the chance of a relapse. The nurses are under such time pressure that they are unable to give this patient the right attention. Nobody is held accountable for future costs. 
A stroke center of a medium sized regional hospital maintains close relation with the local rehabilitation center, the nursing home, and home care organization. Twice a week, they discuss the cases "in the pipeline". That means that rehabilitation can be planned from the moment of hospital admission and that situations can be avoided in which patients have to stay in the hospital, because there is no place in the rehabilitation center or in the nursing home and no capacity for home care.

Box 4: Thinking ahead.

The use of the verb "challenge” may sound rather euphemistic for many change agents in health care. Savitz et al.(2000, p.372) point to the “...existence of financial disincentives to system improvement, that result from traditional accounting practices”. According to them, innovators are often frustrated by the lack of recognition of system savings. They propose to assess the system savings for clinical improvement programs and to use activity-based accounting (Kaplan and Cooper 1998) to attribute them back to the innovating team.

The problems related to the cooperation in the development chain are extensively described in the literature on innovation in industry (for example: Cooper 1994, Den Hertog and Huizenga 2000, Rosenau et al. 1996). The proposed solutions all point in the same direction: multifunctional development teams, stage-gate models for product development, customer involvement, overlapping development phases, etc. Although it seems rather appropriate to look for parallels with industry, one warning might be given. The process of health care is not simply a “delivery system” (cf. Green, Howells and Miles, 2001). Changes in the delivery process de facto constitute changes in the content of the care given. For example, a special outpatient service for suspected breastcancer, the so-called mamma clinics in the Netherlands, not only provides multidisciplinary care, but also faster access and shorter waiting times for test results. Therefore, patient anxiety is reduced and treatment can be started sooner after the initial referral by the GP. Cooperation and communication between health care professionals often results in "different (and more effective) kinds of treatment”. The one-to-one transplants of industrial practices are often (Striem, Ovretveit, and Bommels 2003) not such a success. Practical experience shows that new ways of working have to be rooted in the professional groups in order to raise real engagement. To implement them in the context of health care is not expected to be easy, because different from industry, health care providers are only just beginning to think in terms of processes. The call for professional autonomy is an easy way to shut all doors and fences of functional units for blocking concerted action. 


\section{The vertical axis: echelons of power}

The process described above concerns the organization of the health service at the level of the service organization. It is the level of operations. A lot of problems are solved at this level of the acting professionals: the operation (or: peer) level (figure 2). Continuously numerous decisions have to be made during the care process. De facto, the decisions at the operational level determine to a large extent the actual behavior in a ward or in a service. Many initiatives for clinical improvement (Savitz et al. 2000) can be regarded in this perspective as "grassroots innovations”, implemented by clinicians or clinical teams as remedies for identified problems. The clinical (or: functional) units of health service organizations are traditionally managed by the highest ranking professional. Although new managerial positions next to, or above the position of the chief professional are introduced in many health care organizations, the latter often still dominates the decision-making within the functional units. Management at level 2 plays a crucial role in the introduction of functional innovations: the introduction of new technologies and new medical techniques. This role is twofold. The professionals are both adopters ("recipients”) of new technologies and new techniques and initiators for process innovations and functional innovations. At the same time unit management has the responsibility to implement the managerial policies from level 3: realizing the budget, implementing new management systems and personnel policies.

The unit head reports to the management of the institution, which we shall address as service management or level 3 management. Management has been professionalized to a large extent in the last ten years: at service management level professionals acting as managers are increasingly exchanged for professional managers. The care process is moved to the background. The economics of the institutions, social policy, the regional or national cooperation with other institutions are in the foreground. 


\section{CEILINGS}

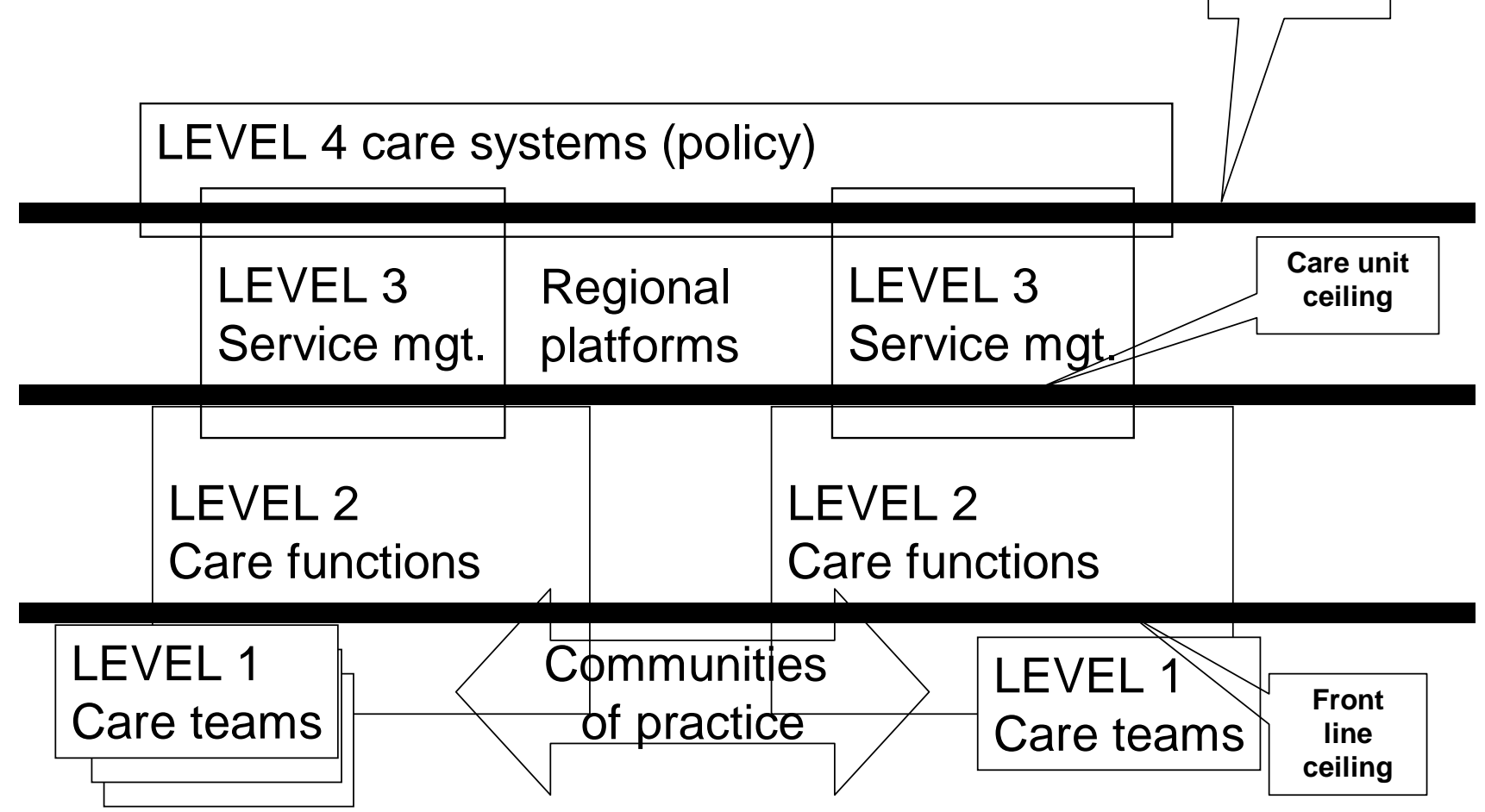

Figure 2: Echelons in health care

The deliberations at this level are often far removed from the content of the care process. The agendas of the board members are filled with meetings with external policy makers of regional or national government, regulators, the insurance companies, and of other institutions. In this way the directors of the health care services sit from time to time at the meeting tables of the next level of decision-making. They are under constant pressure from national and regional policy makers, health care purchasers and insurance companies to reduce costs and support cooperation and share care tasks with other health institutions. The interface between service management and unit management is regarded as a crucial factor in health care innovation. Recent research (Striem et al. 2003, p.256, Adolfini 2003) indicates that one even might speak of the "detachment of management from professional practice”. This divide can be regarded from two perspectives. Striem et al. (2003) suggest that this detachment is greater than in many other knowledge intensive industries. This causes tension 
as physicians are perceived by management to be unwilling to give up part of the control of their professional territory. Consequently, process innovations, which are meant to cross functional borders, are often perceived by the medical staff as “managerial issues”. The agenda is seen as set by management rather than by the professionals. At the same time it is being recognized in the same literature that process innovations like TQM, clinical improvement and re-engineering only make sense, when the physicians take an active role in the change program (see box 5).

The medical superintendent of a psychiatric hospital: "In the beginning of our change process we called in consultants of this well known consultancy firm. They hardly understood anything of our primary process: the care and treatment of patients. A real understanding of that process is key for any change effort. Only once you have that understanding, and know the content of your new design, all those management models and concepts prove their value. So, (...) here you've got our recent implementation plan. You can see, we are going for business process re-engineering".

\section{Box 5: Making sense}

Professionals may hold another perspective. Many innovations (Savitz et al. 2000) are born at the operational level (level 1), and are inspired by shared values of the professionals. Small groups of professional develop solutions for the problems they encounter in the service process. These new solutions mostly require the consent of functional management, and many things can be arranged locally at the operational level, when the professionals are willing to cooperate and no substantial investments are called for. When the initiators aim to transfer their practices, ask for cooperation of other functions and ask for extra budget they often meet the ceiling of the higher echelons. The cited Dutch study into health care innovations (Schrijvers et al. 2003) shows how frustrated the initiators of these bottom-up innovations get by the slow reaction from higher echelons.

The causes of this basic problem have been searched in many directions. The study of Schrijvers et al. (2002) points to multiple factors that slow down the process of change, including: disinterest among managers, rigid financing systems, time pressure at the service 
level. Savitz et al. (2000, p.372) speak in this respect about "the existence of financial disincentives to system improvement”. They hypothesize that institutions would be far more eager to adopt new practices, if there were financial advantages to be gained. In exchange for more funds insurance companies would demand more information about the effectiveness or outcomes of the new schemes. The authors make a plea for more openness about medical performance of health care institutions. Others (Striem et al. 2003) point at the detachment of management from professional practice and the strong resistance of care providers to give up any bit of professional autonomy. This tendency to defend and close off professional territory and to escape from shared responsibility might be regarded as a major barrier for innovation. Conflicts of interest between health care institutions, professional groups, insurance companies, patient-associations and (local) government play an important role too. Or formulated differently: “(...) the benefits and risks of the innovation are distributed unevenly among the people involved” (Denis et al. 2002, p.66). The authors show how innovation patterns in health care are embedded in collective and organizational contexts.

In the worst case the effect can be a real vacuum between level 2 and level 3 . That is the situation when professional and managers are living in separate worlds, without pathways to connect those worlds (see box 6).

The management team of a regional general hospital meets once a month to develop new policies. The process is cast in a seemingly effective form: task groups are set up, their homework is carefully defined and planned. The results are discussed in the medical council, the workers council, and the new policy papers are distributed among the medical and managerial staff. When a policy is defined, it disappears from the agenda of the management team. Nobody is doing a follow up. Moreover, hardly anybody is actively involved with the implementation of the new policies. There appears to be a silent contract: the professionals are not objecting to the new policies as long as they are not forced to implement them. Management won't check their progress in their professional territory, as long as they are not obstructing the policy-making process.

Box 6: Living in different worlds.

A comparative study (Adolfini 2003) in 14 Irish and Italian hospitals shows, that hospital management often constructs formal compliance mechanisms in reaction to institutional 
pressures concerning the quality of health services. They adopt new vocabularies, create new departments and procedures, while the diffusion of the process innovations remains limited to a few single units. By keeping up appearances they charm health purchasers and regulators, without disturbing the local status quo.

Service management (level 3) operates in a similar field of tension. On one hand there is a constant pressure from health purchasers and regulators to reduce cost drastically. Service management has to pass on the bad news to functional management, while room for further traditional cost reductions seems to become smaller and smaller (Volkskrant March $18^{\text {th }}$, 2004). At the same time purchasers and regulators tend to believe strongly in the relevance of managerial ideas: health care services should be run as private firms (Adinolfi 2003). One lesson that has been learned is that physicians should be strongly involved in process innovations (Striem et al. 2003, Lemieux-Charles et al. 2002), even (Striem et al. 2003, p.257) should "take the lead". However, in practice this involvement appears to be absent in many cases (Adinolfi 2003, Striem et al. 2003). The unwillingness to give up part of their professional autonomy has been mentioned already as an underlying cause. In this context the cost reduction and downsizing become easy arguments (Adinolfi 2003) for non involvement: "We don't have the time left”. Service management is also stimulated by policy-makers to make deals with neighbouring health services to pool specialized staff and new expensive technologies. In turn, such measures have to be "sold" to the professionals. The measures might be in flat contradiction with the propositions for innovation and improvement brought forward by the professionals.

Many stakeholders operate on level 4: (regional) government, professional associations, insurance companies, health care purchasers an regulators, patient 's associations, health advocacy and research funding organizations, unions, politicians and other kinds of institutions representing other organizations (university hospitals, for example). The difference between countries with strong private health care markets, like the United States of America and countries with public health care systems is relevant in this respect. The pressure to reduce costs is high in both contexts. Both use regulators try to control costs (Berenson 1991, Reinhardt 1999). Public regulators can use budgeting and price-setting tools for this purpose. In the employer-provided health insurance system in the US regulation is carried out by private health plans. These health plans have the contractual right to regulate the treatments of the insured (Reinhardt 1999). Basically, they control costs by reduction of 
freedom of choice between health care providers. This arrangement has been coined "managed care”. Health plans have adopted a variety of techniques to control cost and making sharp bargains in the purchase of health care services. Many of these techniques have been used under the label of "managed care" within public systems in Europe and other parts of the world (Azevedo 1996).

Service-level innovation has been under-rated by policy-makers as an effective strategy for health care reform (Docter and Oxley 2003). The innovation of health care systems takes place at higher levels. The term innovation in the perspective of policy makers mostly refers to subjects like: universal insurance coverage, financing health care, privatization, adequate and equitable access, allocation of resources and safety inspection. Many writers point to the interrelations between innovations at micro and macro level (Docter and Oxley 2003, Schrijvers et al. 2002). These issues will be elaborated below.

System innovation deals with the institutional and infra-structural measures of the health care industry as a whole. Innovations vary from relatively simple formal measures like the compulsory patient identification before hospital admission, to complex and time demanding redesign of a national insurance system. Legislation and budgeting are main instruments for change. Three broad categories might be useful to describe the innovation landscape at this level. The first one can be labeled as "health care systems reform" (Docteur and Oxley 2003), or "health policy innovation” (Walshe 2001). This reform is meant to deal with the deficiencies of the insurance market. The reform is mainly focused on the introduction of more and more effective (microeconomic) incentives for controlling the performance of the health care system. The introduction of these incentives through the creation of a more competitive environment has proved (Docteur and Oxley 2003) to be difficult because there is a lack of knowledge about the intended and unintended effects. These unintended effects can both originate from a lack of knowledge of the primary process, or by unexpected game playing behavior by patients and care providers (box 7).

The Dutch government intends to shift part of the responsibility for mental health care to the municipalities. The expectation is, that by decentralizing support functions to the municipalities health care will be more effective, solidary, affordable and accessible. In the case of mental care one might 
even hope that this new policy contributes to the emancipation of psychiatric patients. The municipalities can offer a wider range of services for this target group and might get more eye for their citizens who have to deal with the long-lasting effects of their illness. Sweden has introduced a similar policy in the past. To date, this "Swedish model" appears to be in crisis. Especially the problems around chronically psychiatric patients prove to be difficult and complex. Anyway, too difficult and complex for the average municipal welfare worker. The welfare services are not professionally equipped to tackle the problems of the patients effectively. Some municipalities started to employ social psychiatric nurses, but that can hardly have been the initial intention of the policy makers. In that case the patients might as well have remained in the mental health services. The effects of this policy for chronic psychiatric patients have become visible in Sweden: restructuring the care effectively leads to neglect of patients, resulting in deterioration of their physical health and their disappearance from the monitoring activities of the general and mental health services. A more fundamental consequence is, that the right of access to health care is exchanged for the dependency of municipal welfare policy. After: J.C. Hoeveraars (2004). Mr. Hoevenaars is chairmen of the board of mental health services in Groningen (The Netherlands).

"Men are asking for a medicine for vaginal fungi, while they need a remedy for their skin problems." Paul Gebbink, pharmacist in The Hague has seen them in his pharmacy. "The usual variety of Daktarin is not covered by the insurance companies anymore, the one for vaginal use still is. There are physicians who prescribe the vaginal cream instead for men. We don't cooperate with those practices." (Volkskrant, March $\left.12^{\text {th }}, 2004\right)$.

\section{Box 7: Unintended consequences}

Recently, Porter and Olmsted Teisberg (2004) underlined that health care does not function like a normal industry, where competition drives up value for the customer over time as quality improves and costs fall. In contrast, they argue (p. 66), health competition becomes a zero-sum: “The system participants divide value instead of increasing it.” According to Porter and Olmsted Teisberg, competition occurs at the wrong level: the level of the health plans, networks and hospital groups. It should occur in the prevention, diagnosis, and treatment of individual health conditions. "It is at this level that true value is created -or destroyed - disease by disease and patient by patient” (Porter and Olmsted Teisberg 2004 p. 66).

The second category of system innovation deals with general measures to improve the effectiveness of local health care systems. One might speak in this respect of "health care 
management innovations”. These innovations are directed at a broad range of measures: improvement of information about health care, promotion of quality improvement, introduction of modern information and communication technologies, support for research, experimentation and diffusion of best practices.

The last type of system innovation is focused on the improvement of regional health care system. Cooperation and integration of local health care services serve to improve the functioning of the health care value chain. These efforts are aimed at developing crossinstitutional patterns of action or "integrated clinical pathways". One might think about the agreements (figure 1) between hospitals, rehabilitation centers and home care about the policy for the treatment of patients with specific health problems.

Service management plays an important role on the systems level of innovation as well. A quick look in the agenda's of board members will show that most of their time is filled with appointments with representatives from other institutions. No wonder there is so little time to develop dialogues inside the own organization. The cooperation with neighbouring health care services appears to be a time-consuming process.

The system level is both the level of interacting bureaucracies, as the open political arena where almost each group of stakeholders plays its role. Again one hears policy makers complain about the resistance to change among professionals, service managers and local policy makers. At the same time the latter need little encouragement to give colourful accounts of the madness in the system.

\section{Better practice}

Our exploration of both literature and practice shows many walls and ceilings in the health care innovation system. The walls in this metaphor refer to the borders between functional domains in the innovation process and the ceilings to the demarcations between system levels. This explorative study indicates that walls and ceilings create serious barriers for the diffusion and implementation of innovation in health care services. Using a systems' perspective appeared to be helpful for mapping these barriers, and (cf. Carlsson et al. 2002) for unravelling the process of innovation and diffusion within health care. The use of systems 
theory also helps to understand the mechanisms that hamper innovation performance in the industry. Two of these mechanisms are identified in this study. Both are dealing with the malfunctioning of the feedbacks in the system. The first mechanism is connected with the walls between the functions (disciplines or services) along the health care value chain. Most of the feedbacks are predominantly concerned with throughput and output measures within functional domains and do not regard the throughputs and outputs of the value chain (or "care process”) as a whole. The effect is sub-optimization. Box 4 exemplified the differences between piece meal and integrated (anticipatory) feed back systems.

The second mechanism that limits the performance of the innovation system in health care concerns the vertical dimension of the system. Innovations can take place at different levels of the system. This study identified four relevant levels: the operational level, functional or unit level, the service management level and the system or policy level. The basic problem is that the impacts of the interventions are often only established at the level of the intervention. Consequently the agents of change remain uninformed about the effects on higher or lower system levels. Policy measures at the national level (box 7) may have unintended consequences at the operational level. On the other hand, innovations at the operational and functional level might often require complementary measures at the management and system level. Experiments with long term objectives might for example require extra funds or consent from health care inspection and regulators.

These mechanisms should be recognized in efforts to improve the performance of the innovation system. Three approaches to tackle the situation can be discerned as a result of this study. The first deals with the translation of the idea of evidence-based medicine to the practice of organizational change: evidence based change. The second stresses the importance of innovation coalitions, which involve actors across the walls and ceilings of the health care system. The last approach underlines the multilevel character of health care innovation.

Evidence-based change. After years of advocacy and evaluation research, ideas about evidence-based medicine (Sackett 1997) are beginning to take root in health care. Not so much as a common practice, but as a direction for health care-development in the near future. The same logic of using scientific data as much as possible to direct medical practice seems to apply to innovations at the service and system level. It is all too clear that many measures 
don't have the long-term effects they were designed for. We are discovering, for example (Porter and Olmsted Teisberg 2004) that new incentives to reduce costs, in fact make costs rise. To date we lack the access to information about these effects. The walls and ceilings play an important role in this respect. Policy-makers, managers, professionals are in an urgent need of information about the effects of new treatment strategies and new organizational processes in which they are embedded (Haines and Iliffe 1995, Porter and Olmsted Teisberg 2004). Furthermore, they need the same kind of information to monitor change processes in their own organizations. As one our interviewees, psychiatrist and general director of a psychiatric hospital formulated: “You don't have a change process without measuring change. Without measurement it is all fake.”

The innovative coalition. The diffusion study of Denis et al. (2002) indicates that the pace of diffusion is accelerated when there is a strong pro-innovation coalition. That means that different stakeholders (managers, clinicians, patients, insurers) share benefits and risks. Other studies (Adolfini 2003, Lemieux-Charles et al. 2002, Striem et al. 2003) stress that the shared responsibility and involvement of both management and clinicians is crucial for effective implementation. Otherwise the risk arises (Adolfini 2003) that improvement policies become separated from practice. In other words (Striem et al. 2003): the ownership of change has to be shared between clinicians and administrators at all levels and functions of the system. The focused factories in our field study were built by strong cross-functional teams, with many physicians among the helmsmen. It might be expected that the role of the patients, family and volunteer aid also changes in this development: from receiver to co-developer.

Multilevel change. Primarily, the analysis above focuses on the boundaries (or “ceilings”) between the echelons of health care. That doesn’t mean that good examples of cross-level innovation cannot be found. A good example (Lemieux and Blidner 2002) is the regional experiment with the Coordinated Stroke Strategy (CSS) in Canada. This pilot study in four regions was initiated by The Heart and Stroke foundation in Ontario, a voluntary research and grant body. The Ministry of Health funded the project, while a professional dissemination network had been instrumental in the diffusion and implementation of the new approach for the treatment of acute strokes. Actors at the different levels played different roles. The advocacy organization was the initiator and invested resources for dissemination and implementation of CSS. The necessary structural changes to stroke care, and the clinical and system changes could not be sustained without provincial government support. The 
diffusion of CSS would also not have been possible without intensive cooperation between various health care services. Service management played an important role in realizing that cooperation. Functional leadership, and their professional associations had a role in shaping the clinical content of the program, and clinical staff had to be prepared for the new practice. One might argue that diffusion of health care innovations requires multiple level- and cross level-decision making embedded in a collective organizational context. Grass root innovation has little chance without support from senior management (Savits et al. 2000). At the same time it has been made clear (Striem et al 2003) that broader change programs without commitment of the professionals don't make sense either.

Best practice examples, like the ones described in the study of Schrijvers et al. (2002) are very useful in showing that alternatives for malfunctioning practice do exist. However, they have a limited value for guiding wide scale implementation. Our study indicates that wide scale implementation of better practice requires a deep understanding of the horizontal and vertical dimensions of the innovation process.

\section{Conclusions}

Service innovation is a field of growing interest for innovation researchers. However, the research is still in its infancy. Pioneers in the field of service innovation research (Coombs 2004, Miles 2004, Tether and Metcalfe 2003) have pointed at the limited value of concepts, models, and typologies from the manufacturing industry for understanding innovation in the service sector. It is argued in this paper, that the same holds for the research into innovation in health care services. In this domain our knowledge is still fragmented, and we lack common frameworks, like for example Pavitt’s (1984) well-know sectoral taxonomy, and Cooper's (1994) stage-gate models. Our research practice in two EU-funded network programs (Publin and INNOFLEX) indicated that such conceptual instruments are of great use in the comparison and integration of studies from various contexts.

The huge pressure to reform the health care industry creates a strong need for knowledge that supports that change. Health care innovation tends to be a complex of interrelated functional (or: clinical), process improvements and systemic changes. In this development, diffusion and implementation appear to be the vulnerable phases. This paper, 
based on a literature survey and an explorative study, has aimed to contribute to the understanding of the forces that drive and block the development, implementation and diffusion of health care innovation. For this purpose a two dimensional framework has been presented, which makes it possible to "map” the innovation and its development process within the wider context of health services, health processes and health systems. Considering the early development stage of health innovation studies, the mapping metaphor (Christensen 2000) seemed more appropriate than a static taxonomy.

This exploratory study indicates that future researchers should be aware of the multilevel character of health care innovation. Cross-level cooperation appears to be crucial in realizing the full potential value of new techniques, technologies, processes and systems. For that purpose (Denis et al. 2002) an insight in the distribution of benefits and risks originating from the new practice is needed. Furthermore this study hopes to encourage innovators, either working at the grassroots or at policy level, to invest in building pro-innovation coalitions, which base their cooperation on evidence of patient- and service outcomes. Finally, it has to be stressed that innovation in health care is basically a process of organizational and interorganizational learning. The creation of new structures for disseminating evidence appears to be an insufficient condition for its dissemination. It is essential (cf. Lemieux-Charles et al. 2003) that settings are created in which professionals, managers and policy-makers join to develop collective knowledge. 


\section{References}

Adonolfi, P. (2003). Total quality in public health care: a study of Italian and Irish hospitals. Total Quality Management, 14 (2) 141-150.

Adler, P.S., Riley, P., Kwon, Seok-Woo, Singer, J., Le, B., and Satrasala, R. (2003). Performance improvement capacity: Keys to accelerating performance improvement in hospitals. California Management Review, 45 (2) 12-33.

Azevedo, D. (1996). America’s latest export: Managed care. Medical Economics, 72 (23) 71-72, 74, 79.

Blendon,R, Schoen, C., Desroches, C., Osborn, R., Scoles, K. and Zapert, K. (2002). Inequities in health care: a five-country survey. Health Affairs, 21(3) 182-190.

Burke, R.J. (2003). Hospital restructuring, workload, and nursing staff satisfaction and work environment, Health Care Manager, 22(2) 99-107.

Carlsson, B., Jacobsson, S., Holmén, M., and Rickne, A. (2002). Innovation systems: Analytical and methodological issues. Research Policy 31 233-245.

Carson, K.D., Phillips Carson, P. and Yallapraqgada, R. (2001). Teamwork or interdepartmental cooperation: Which is more important in the health care setting? Health care Manager, 19(4) 39-46.

Casalino, L.P., Devers, K.J., and Brewster, L.R. (2003). Focused factories? Physicianowned specialty facilities. Health Affairs, 22(6)56-67.

Christensen, C.M. (2000). Making strategy: Learning by doing. Harvard Business Review, 78(6) 141-156.

Christensen, C.M., Bohmer, R., and Kenagy, J. (2000). Will disruptive innovations cure health care? Harvard Business Review, 78(5) 102-112.

Coombs, R. (2004). The changing character of "service innovation" and the emergence of "knowledge-intensive business services”. In: B. Dankbaar (ed.). Innovation management in the knowledge economy, London: Imperial College Press.

Cooper, R.S. (1994). Third generation new product process. Journal of Production Innovation Management, 11(1) 3-15.

Den Hertog, J.F. and Huizenga, E. (2000). The knowledge enterprise, The implementation of intelligent business strategies. London: Imperial College Press. 
Denis, J.L., Hébert, Langley, A., Lozeau, and Trottier, L.H. (2002). Explaining diffusion patterns for complex health care innovations. Health care management Review, 27(3) 60-73.

Docteur, H.R.E. and Oxley (2003). Health care systems: The lessons from the reform experience. OECD Working Papers. OECD: Paris.

Eisenhardt, K. (1989). Building theories from case study research. Academy of Management Review, 14(4) 532-550.

Engelstad, P.H. and Gustavsen, B. (1993). Swedish network development for implementing national work reform strategy. Human Relations, 46(2) 219-246.

Field, M. and Lohr, K.N. eds. (1992). Guidelines for clinical practice: From development to use. Washington D.C. : National Academy press.

Fuchs, V. and Garber, A.M. (2003). Medical innovation: Promises and pitfalls. The Brooking Review, 21(1) 44-48.

Ho, S. K. Chan, L. and Kidwell jr, R.E. (1999). The implementation of Business Reengineering in American and Canadian hospitals. Health Care management Review, 24 (2), 19-31..

Hoevenaars, J.C. (2004). Column, Psy, (4) 19.

Kaplan, R.S. and Cooper, R. (1998). Cost \& effect, Using integrated cost systems to drive profitability and performance. Boston: Harvard Business School Press.

Kohn, L.T., Corrigan, J.M., and Donaldson, M.S. (eds.) (2000). To err is human: Building safer health systems. Washington: National Academy Press.

Lemieux-Charles, L. and McGuire, W. and Blidner, I. (2002). Building interorganizational knowledge for evidence-Based Health system change. Health Care Management Review, 27 (3), 48-59.

McLaughlin, C.P. and Kaluzny, A.N. (2000). Building client centered systems of care: Choosing a process direction for the next century. Health Care Management review, 25 (1) 75-82.

Metcalfe, J.S. and James, A. (2001). Emergent innovation systems and the delivery of clinical services: The case of intra-ocular lenses, an ESSY Working Paper, CRIC, University of Manchester.

Miles, I. (2004). Service innovation: Coming age in the knowledge-based economy. In: B. Dankbaar (ed.). Innovation management in the knowledge economy, London: Imperial College Press. 
Mintzberg, H., (1979). The structuring of organizations. Prentice Hall: Englewood Cliffs, N.Y.

Pavitt, K. (1984). Sectoral patterns of technical change: Towards a taxonomy and a theory. Research Policy, 13 (6) 343-373.

Reinhardt, U.E. (1999). The predictable managed care Kvetch on the rocky road from adolescence to adulthood. Journal of Health Politics, Policy and Law, 24 (5) 897-910.

Pfeffer, J. and Sutton, R.I. Sutton, R.I. (2000). The knowledge doing gap, How smart companies turn knowledge into action. Boston: Harvard Business School Press.

Robinson, D.F., Savage, G.T., and Campbell, K.S. (2003). Organizational learning, diffusion of innovation, and international collaboration in Telemedicine. Health Care Management Review, 28(1) 68-78.

Sackett, D.I. (1997). Evidence-based medicine. New York: Churchill-Livingstone.

Schrijvers, G., Oudendijk, N., De Vries, P., Hagemans, M. (eds.) (2002). Moderne patientenzorg in Nederland, Van kennis naar actie. Reed Elsevier, Amsterdam.

Simpson, R. L. (2003). Back to basics with IT and patient-centered care. Nursing Management, 34 (4) 14-16).

Sherer, J.L. (1993). Putting patients first: Work to define Patient-Centered-Care. Hospitals, 67 (Febr.) 1-18.

Strauss, A. and Corbin, J. (1990). Basics of qualitative research: Grounded theory, procedures and techniques. Newbury Park: Sage.

Striem, J., Øvretveit, and Brommels, M. (2003). Is health care a special challenge to quality management? Insights from the Danderyd Hospital case. Quality Management in Health Care, 12 (4) 250-258.

Tabak, F., and Jain, B.A. (2000). Predicting hospital innovativeness: An exploration of the perceived organizational context. Journal of Applied Management Studies, 9 (2) 217-233.

Tether, B. and Metcalfe, J.S. (2003). Services and services innovation, CRIC Working Papers Series, Discussion paper 58, Manchester: CRIC.

Timmermans, S. and Berg, M. (2003). The gold standard: The challenge of evidencebased medicine and standardization. Philidelphia: Temple University Press.

Tucker, A.L. Tucker and Edmondson, A.C. (2003). Why hospitals don't learn from failures: Organizational and psychological dynamics. California Management Review, 45 (2) $55-72$.

Voelker, R. (2003). Specialty hospitals generate revenue and controversy. Journal of the American Medical Association, 35 (4) 409-410. 
Walshe, K. (2001). Don't try this at home: Health policy lessons for the NHS from the United States. IEA, Economic Affairs, (December) 28-31.

Wenger, E. (1998). Communities of practice: Learning, meaning and identity. New York: Cambridge University Press.

Wholey, D.R., Padman, R., Hamer, R., and Schwartz, S. (2000). The diffusion of information technology among health maintenance organizations. Health Care Management Review, 25(2) 24-33.

Williams, E.S., Konrad, Th.R., Scheckler, W.E., Pathman, D.E., Linzer, M., McMurray, J.E., Gerrity, M., and Schwartz, M. (2001). Understanding physicians’ intention to withdraw from practice: The role of job satisfaction. Health Care management Review, 26(1) 7-19. 